This item was submitted to Loughborough's Research Repository by the author.

Items in Figshare are protected by copyright, with all rights reserved, unless otherwise indicated.

\title{
Surface energy measurements of coated titanium dioxide pigment
}

PLEASE CITE THE PUBLISHED VERSION

PUBLISHER

(C) Elsevier

LICENCE

CC BY-NC-ND 4.0

\section{REPOSITORY RECORD}

Lim, Boon-Cheng, Noreen L. Thomas, and I. Sutherland. 2008. "Surface Energy Measurements of Coated Titanium Dioxide Pigment”. figshare. https://hdl.handle.net/2134/3263. 


\title{
Surface Energy Measurements of Coated Titanium Dioxide Pigment
}

\author{
B. C. Lim, N. L. Thomas and I. Sutherland \\ Institute of Polymer Technology \& Materials Engineering, \\ Loughborough University, Loughborough, Leicestershire, LE11 3TU, UK.
}

\begin{abstract}
In this study surface energy measurements have been carried out on titanium dioxide pigments coated with different types of organic compound. The organic coatings investigated were polymethylsiloxane and octyl triethoxy-silane. The level of coating applied was increased from 0.2 up to 1.5 weight $\%$. Contact angles were measured using an advancing sessile drop method. To allow for the fact that measurements were made on pressed discs of particles rather than on a perfectly flat surface, a correction was applied to convert each measured contact angle to the true Young's contact angle. Surface energies were calculated from the corrected contact angles using the Owens and Wendt equation. From the values of surface energy it was possible to determine at what coating level the surface characteristics changed from hydrophilic to hydrophobic and hence when complete coverage had taken place. For both the siloxane and the silane coatings it was found that complete coating coverage occurred at an addition level of around 0.8 weight $\%$. The surface energies of all the coated pigments were found to correlate well with their dispersion behaviour in liquid paraffin.
\end{abstract}

Keywords: Titanium dioxide; surface energy; contact angle; organic coating 


\section{Introduction}

Titanium dioxide, $\mathrm{TiO}_{2}$ is the most important inorganic pigment used in the plastics and paint industries, comprising over $65 \%$ of the total consumption in different applications. Most commercial $\mathrm{TiO}_{2}$ pigments are treated with some form of surface coating. The most widely used coating is alumina and many general-purpose grades are treated only with alumina, at levels between 0.5 and 3.5 weight $\%[1,2]$. This treatment promotes dispersion of the pigment and retards unwanted photodegradation reactions between the pigment and the polymer matrix. Although $\mathrm{TiO}_{2}$ absorbs strongly in the ultra-violet from $270-420 \mathrm{~nm}$ and therefore protects polymers from photochemical degradation, it is also photoactive and can give rise to photocatalytic degradation of polymers [3-5]. This erosion of the polymer surface is commonly called 'chalking'. Where enhanced resistance to weathering is required, silica coatings are used in addition to alumina. This combination provides an effective barrier to reduce the photodegradative effect of $\mathrm{TiO}_{2}$ on plastics and paints for exterior use $[1,2,6]$.

Many modern $\mathrm{TiO}_{2}$ pigments are also treated with organic compounds. The hydrophilic inorganic-coated pigments are treated with organic compounds thus creating hydrophobic surfaces. These organic coatings serve to reduce agglomeration of pigment particles and to prevent absorption of water during storage. They also improve compatibility of the pigment with organic substrates and hence promote better dispersion of the pigment in the polymer matrix. The types of organic compounds commonly used as surface treatments on $\mathrm{TiO}_{2}$ are polyols, amines, siloxanes and phosphated fatty acids [1].

In the current study, a series of titanium dioxide pigments have been coated with different types and amounts of organic compound. These coated pigments have then 
been analysed by determining their surface free energies from contact angle measurements.

Figure 1 is a schematic diagram showing the contact angle $(\theta)$ made by a liquid drop on a smooth, planar surface. The basic equation to describe the balance of energies controlling the contact angle of the liquid drop on such a surface is known as Young's equation [7] and is one of the oldest in surface science. Young's equation is given below (equation 1) where $\gamma$ is the surface free energy and subscripts ' $S$ ' and ' $L$ ' stand for solid and liquid respectively.

$$
\gamma_{\mathrm{S}}=\gamma_{\mathrm{SL}}+\gamma_{\mathrm{L}} \cos \theta
$$

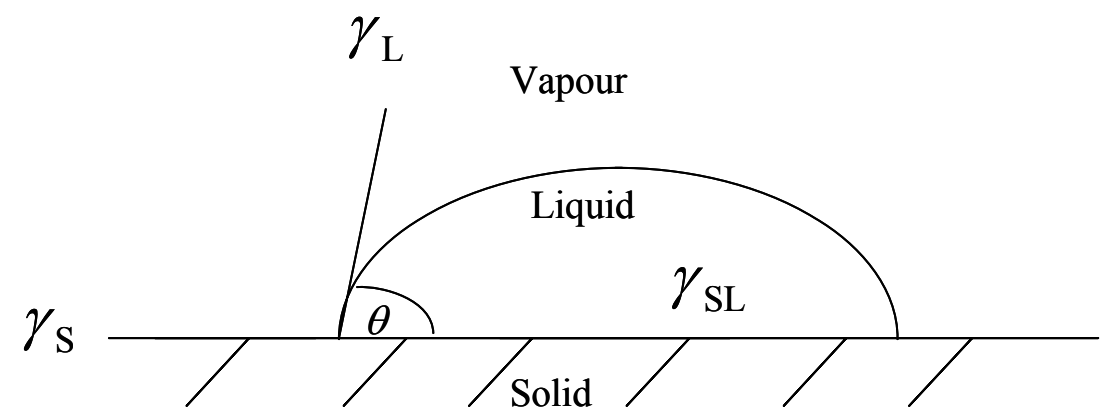

Figure 1. Schematic diagram of a liquid drop on a surface

Dupré [8] proposed the idea of the thermodynamic work of adhesion $\left(\mathrm{W}_{\mathrm{ad}}\right)$, which is the reversible work done in separation of unit area of a solid/liquid interface.

The Dupré equation states that: -

$$
\mathrm{W}_{\mathrm{ad}}=\gamma_{\mathrm{S}}+\gamma_{\mathrm{L}}-\gamma_{\mathrm{SL}}
$$

Combining equations 1 and 2 gives the Young-Dupré equation: -

$$
\mathrm{W}_{\text {ad }}=\gamma_{\mathrm{L}}(1+\cos \theta)
$$


Fowkes [9] suggested that the total surface free energy of a solid or a liquid is the sum of three different intermolecular forces. They are dispersion $\left(\gamma^{\mathrm{d}}\right)$, polar $\left(\gamma^{\mathrm{p}}\right)$ and hydrogen bonding $\left(\gamma^{\mathrm{h}}\right)$ surface energies. Often $\gamma^{\mathrm{p}}$ and $\gamma^{\mathrm{h}}$ are encompassed in a single term known as $\gamma^{\mathrm{p}}$. He also derived the interfacial free energy of a solid and a liquid that interacted solely by dispersion forces: -

$$
\gamma_{\mathrm{SL}}=\gamma_{\mathrm{S}}+\gamma_{\mathrm{L}}-2\left(\gamma_{\mathrm{S}}^{\mathrm{d}} \gamma_{\mathrm{L}}^{\mathrm{d}}\right)^{1 / 2}
$$

For cases where both solid and liquid are polar, Owens and Wendt [10] and Kaelble [11] combined the Fowkes and Young-Dupré equations: -

$$
\gamma_{\mathrm{L}}(1+\cos \theta)=2\left(\gamma_{\mathrm{S}}^{\mathrm{d}} \gamma_{\mathrm{L}}^{\mathrm{d}}\right)^{1 / 2}+2\left(\gamma_{\mathrm{S}}^{\mathrm{p}} \gamma_{\mathrm{L}}^{\mathrm{p}}\right)^{1 / 2}
$$

Contact angles measured using two liquids (one polar and one non-polar) can be used to determine the polar and dispersive components of the surface free energy following the method of Owens and Wendt [10]. This approach has been widely used to measure wettability, surface energy and adhesion properties of polymers [12]. Examples include studies of surface treated polyolefins for painting or printing [13] and oxidised carbon fibres to enhance their reinforcing properties [14]. This approach has also been used to investigate surface modified montmorillonite for tailored interfaces in nanocomposites [15].

In this study contact angle measurements were made on pressed discs of coated $\mathrm{TiO}_{2}$ particles. To allow for the fact that measurements were made on pressed particles rather than on a perfectly flat surface, a relationship was derived between the measured contact angle and the true Young's contact angle (see section 2.2 below). Software based on the Owens and Wendt equation was used to calculate surface energies of coated titanium dioxide pigment from the corrected contact angle measurements. 


\section{Experimental}

\subsection{Organic Coating of $\mathrm{TiO}_{2}$ Pigment}

A rutile $\mathrm{TiO}_{2}$ coated with an inorganic coating (silica and alumina) was selected. This material was provided by Huntsman Pigments and had a surface area determined by BET analysis of $11-12 \mathrm{~m}^{2} / \mathrm{g}$. Two types of organic compound were used. Each compound type was coated onto a sample of pigment at a series of different concentrations. Spray coating was carried out using solutions of the appropriate concentration of the organic compound dissolved in industrial methylated spirit (IMS). The coated pigments were then micronised.

The following organic coated pigments were produced: Polymethylsiloxane: $0.3 \mathrm{wt} \%, 0.5 \mathrm{wt} \%, 0.8 \mathrm{wt} \%$, and $1.5 \mathrm{wt} \%$ Octyl triethoxy-silane: $0.2 \mathrm{wt} \%, 0.5 \mathrm{wt} \%, 0.8 \mathrm{wt} \%$, and $1.2 \mathrm{wt} \%$.

\subsection{Contact Angle Measurements}

Contact angle tests were carried out using Dataphysics OCA-20 contact angle equipment. Water and diiodomethane (DIM) were used as the two testing liquids. Five pressed discs were made from each sample of coated pigment and these were taken as the substrates upon which contact angles of the liquid drops were measured. An advancing sessile drop method was used for the contact angle measurements.

Conventional contact angle measurement methods rely on surfaces being perfectly flat and smooth. However, in these studies contact angles were measured on compacted particles rather than on a perfectly flat surface and so it was necessary to employ a correction factor to allow for this. A relationship was derived between the 
apparent contact angle, $\phi$, which is the macroscopic value observed in the low power microscope, and the true Young's contact angle, $(\theta)$. This derivation is discussed below.

In this treatment the drop is assumed to be in thermodynamic equilibrium on a heterogeneous surface. As the drop expands across the pressed powder disc additional liquid surface is created as the liquid spans the gaps between the particles.

Firstly, consider a surface consisting of close-packed spherical particles of radius, $R$, as shown in Figure 2. Imagine a drop of liquid expanding over an area 'A', which is the unit cell of the close-packed surface. 'A' is the apparent area over which the drop has advanced (taking the surface, from a macroscopic point of view, as flat) and is given by: -

$$
A=2 \sqrt{3} R^{2}
$$

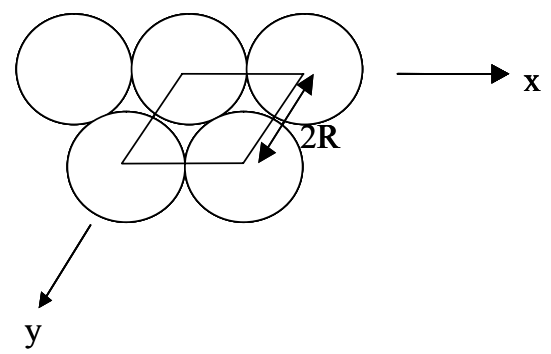

Figure 2. Plan View of Close-packed Powder

The liquid expands over the top of the particles creating a solid-liquid interface and the thermodynamic contact angle, $\theta$, is as shown in Figure 3.

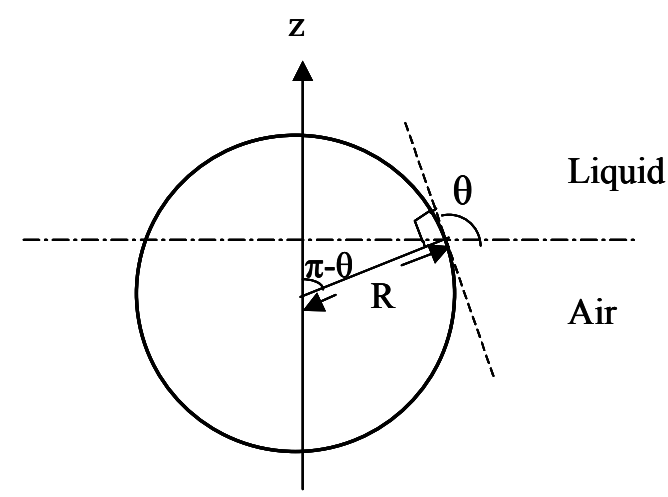

Figure 3. Cross-section through Particle 
Hence, as illustrated in Figure 4, the actual area of solid-liquid interface created, $\mathrm{A}_{\mathrm{SL}}$, is given by: -

$$
\mathrm{A}_{\mathrm{SL}}=\int_{0}^{\pi-\theta} 2 \pi \mathrm{R} \cdot \sin \alpha \cdot \mathrm{R} \cdot \mathrm{d} \alpha=2 \pi \mathrm{R}^{2}[1-\cos (\pi-\theta)]
$$

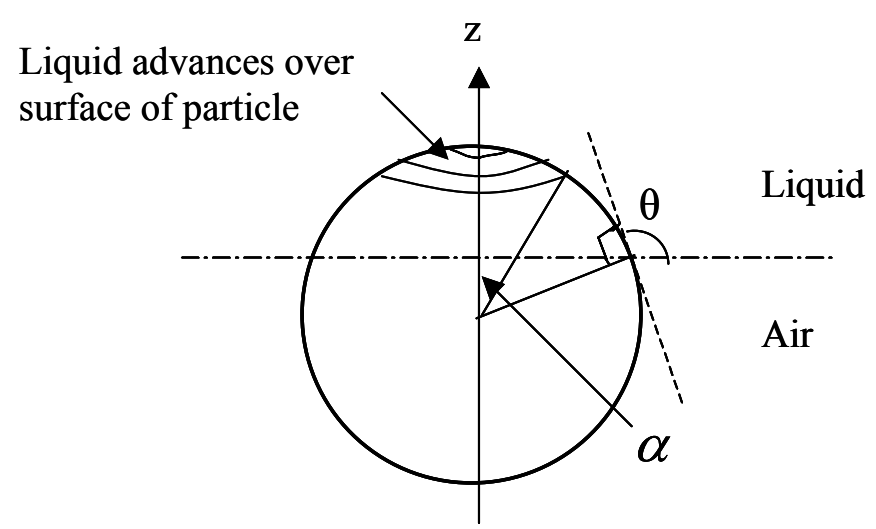

Figure 4. Liquid advances over the Surface of a Particle

The area of solid surface consumed, $\mathrm{A}_{\mathrm{S}}$, is given by equation 8: -

$$
\mathrm{A}_{\mathrm{S}}=\mathrm{A}_{\mathrm{SL}}
$$

The area of the liquid-air interface created, $A_{L}$, is given by: -

$$
\mathrm{A}_{\mathrm{L}}=2 \sqrt{3} \mathrm{R}^{2}-\pi \mathrm{R}^{2} \sin ^{2}(\pi-\theta)
$$

Since all 'A' are small, for thermodynamic equilibrium, it follows that: -

$$
\mathrm{A}_{\mathrm{S}} \gamma_{\mathrm{S}}=\mathrm{A}_{\mathrm{SL}} \gamma_{\mathrm{SL}}+\mathrm{A}_{\mathrm{L}} \gamma_{\mathrm{L}}+\mathrm{A} \gamma_{\mathrm{L}} \cos \phi
$$

where $\phi$ is the apparent contact angle and $\gamma_{\mathrm{S}}, \gamma_{\mathrm{L}}$ and $\gamma_{\mathrm{SL}}$ are surface and interfacial energies.

For a flat surface, Young's equation is valid i.e.: -

$$
\gamma_{\mathrm{S}}=\gamma_{\mathrm{SL}}+\gamma_{\mathrm{L}} \cos \theta
$$


From equations $6,7,8,9$ and 1 , the values for $A_{S}, A_{L}$ and $A_{S L}$ may now be calculated as a function of $\theta$, for this specific geometric arrangement, and substituted into equation 10. This allows a relationship to be established between the measured or apparent contact angle $(\phi)$ and the true Young's contact angle $(\theta)$. The result is given in equation 11. This relationship is independent of particle size.

$$
\cos \phi=\frac{\pi}{2 \sqrt{3}} .(1+\cos \theta)^{2}-1
$$

The relationship between measured contact angle $(\phi)$ and Young's contact angle $(\theta)$ is plotted in Figure 5.

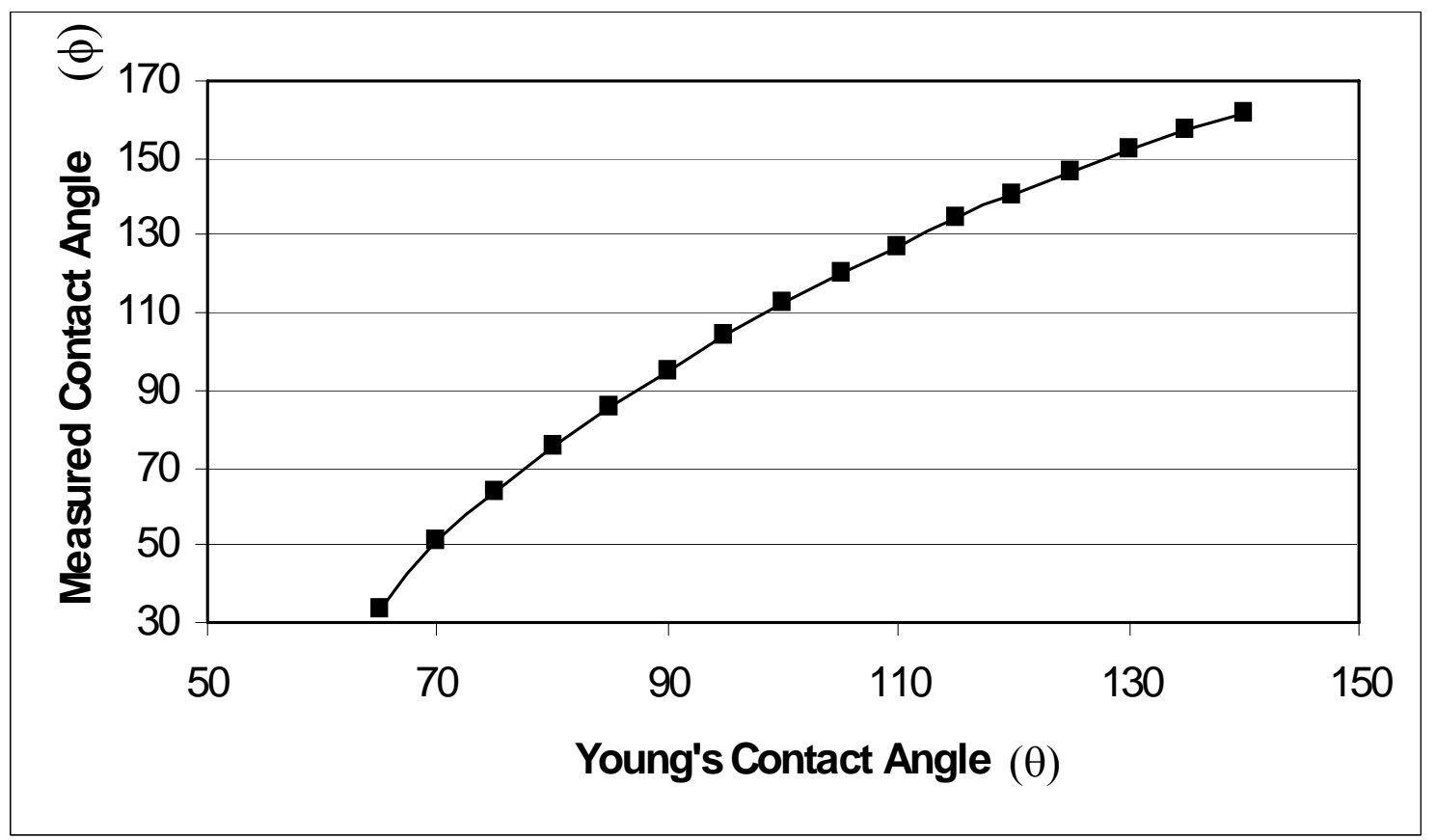

Figure 5. Relationship between measured $(\phi)$ and Young's contact angles $(\theta)$

\subsection{Dispersion Tests}

A tiny amount of each coated pigment was dispersed in liquid paraffin and then viewed in transmitted light in a Leica optical microscope. 


\section{Results and Discussion}

\subsection{Contact Angle Measurements}

The results of contact angle measurements for all the different coated pigments are given in Table 1. These are corrected contact angles using the expression derived in equation 11. It is seen that the contact angles measured using diiodomethane remain reasonably constant, whereas the contact angles measured with water increase as the coating level increases for each organic compound. When the contact angle of water on a surface is greater than $90^{\circ}$, the surface is not wetted by the water i.e. the surface is hydrophobic. The results for both coating types show that when the coating level reaches $0.8 \mathrm{wt} \%$, the contact angle with water has exceeded $90^{\circ}$, showing that the particle surfaces have become hydrophobic.

Table 1 also shows values of surface energy. The total surface energy $\left(\gamma_{\mathrm{s}}\right)$ is the sum of a dispersive component $\left(\gamma^{\mathrm{d}}\right)$ and a polar component $\left(\gamma^{\mathrm{p}}\right)$. It is seen that the polar surface energies reduce with increasing coating level. The point at which the polar surface energy tends towards zero indicates the point at which the surface is non-polar and complete coating coverage has occurred. For both the siloxane-coated and silanecoated pigments, non-polarity was achieved at a coating level of $0.8 \mathrm{wt} \%$. Graphs of polar surface energy as a function of coating level for both coating types are plotted in Figures 6 (a) and (b) respectively.

Note that the value of $\gamma^{\mathrm{d}}$ of $23 \mathrm{mJm}^{-2}$ for polymethylsiloxane found in this study is in good agreement with the value of $\gamma^{\mathrm{d}}$ of $21.7 \mathrm{mJm}^{-2}$ for polydimethylsiloxane reported by Owen and Wendt [10]. 


\subsection{Dispersion Tests}

Results of dispersion tests with samples of the pigments in liquid paraffin correlated well with the surface energy measurements. Examination of samples in transmission in the optical microscope showed that as the organic coating level increased there was reduction in agglomeration of the pigments - and hence improved dispersion. Good dispersion, as judged by visual observation, was achieved for both organic compound types at a coating level of 0.8 weight $\%$, which was the level at which surface energy measurements had shown the pigment surface to have changed from hydrophilic to hydrophobic.

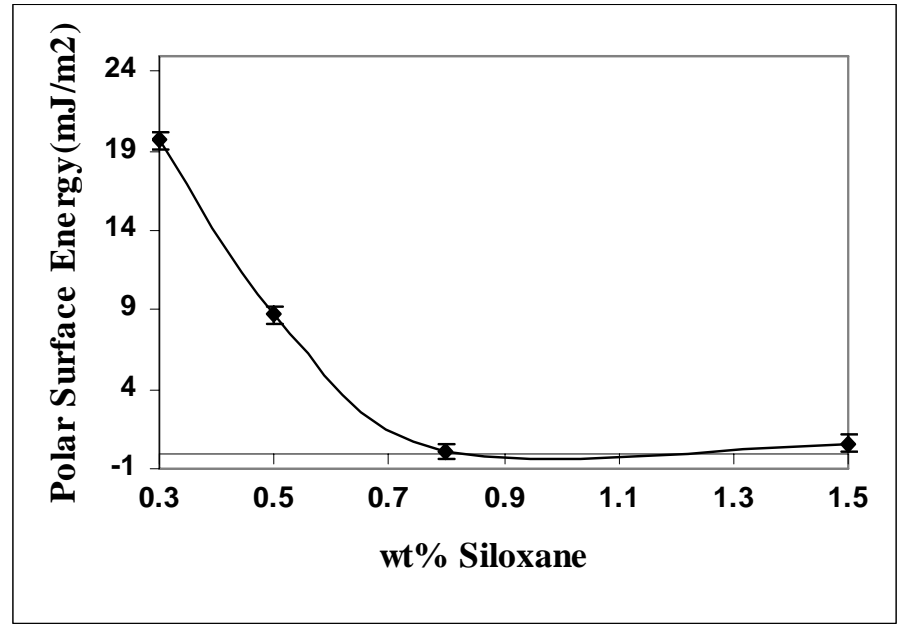

Figure 6 (a) Polar Surface Energy as a Function of Siloxane Coating Level

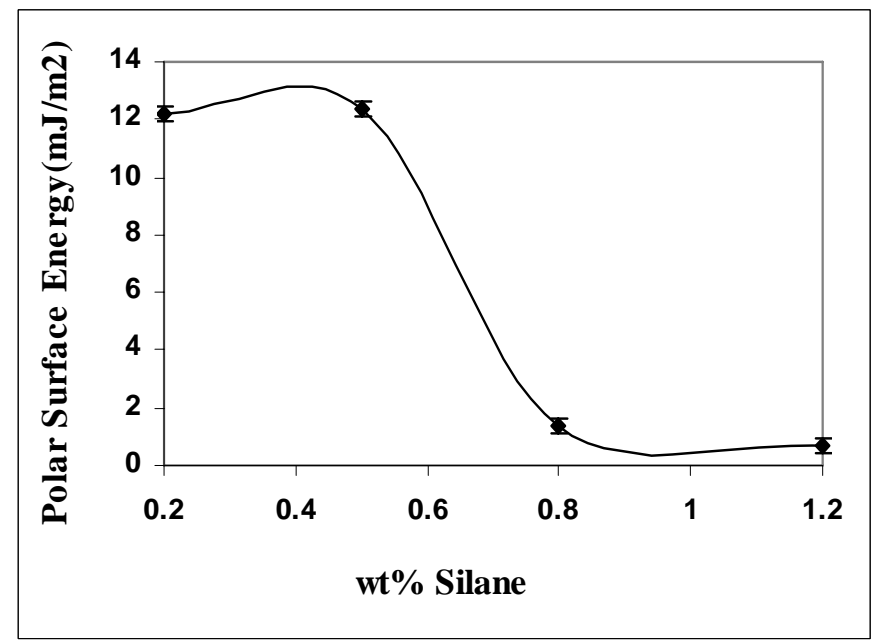

Figure 6 (b) Polar Surface Energy as a Function of Silane Coating Level 
Figures 7 (a) and (b) show optical micrographs taken from pigment samples coated with different level of siloxane and silane respectively dispersed in liquid paraffin. It is seen that in both sets of micrographs pigments appear agglomerated until a coating level of $0.8 \mathrm{wt} \%$ is reached. For coatings of this level and above good dispersion is achieved.

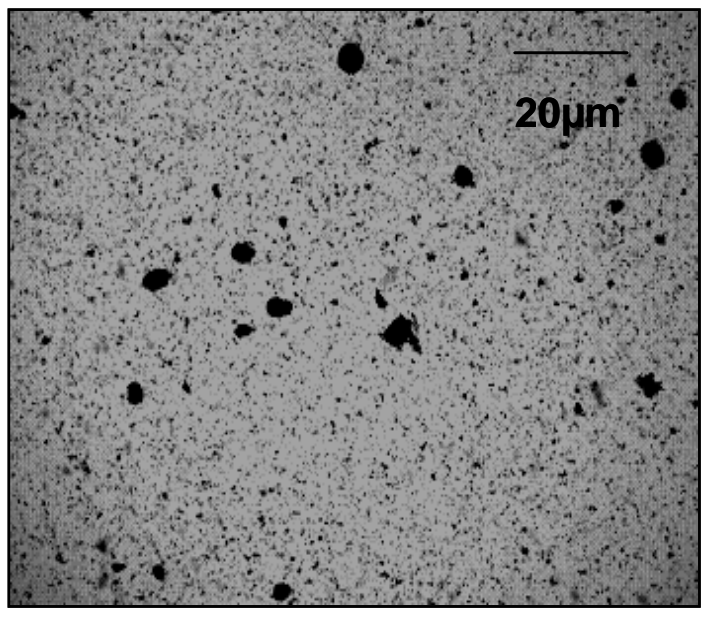

$0.3 \%$ Siloxane

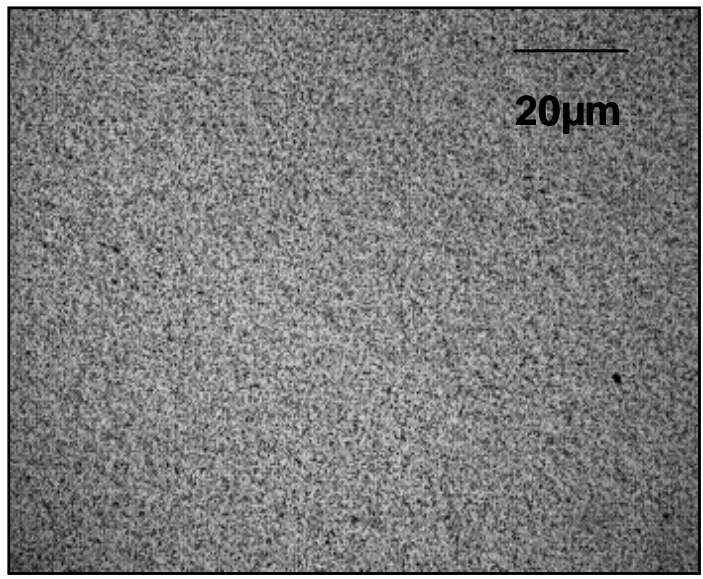

$0.8 \%$ Siloxane

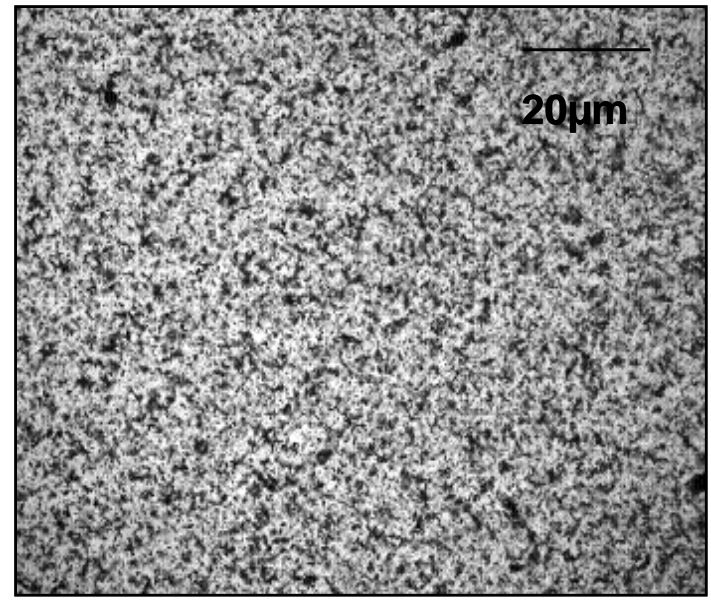

$0.5 \%$ Siloxane

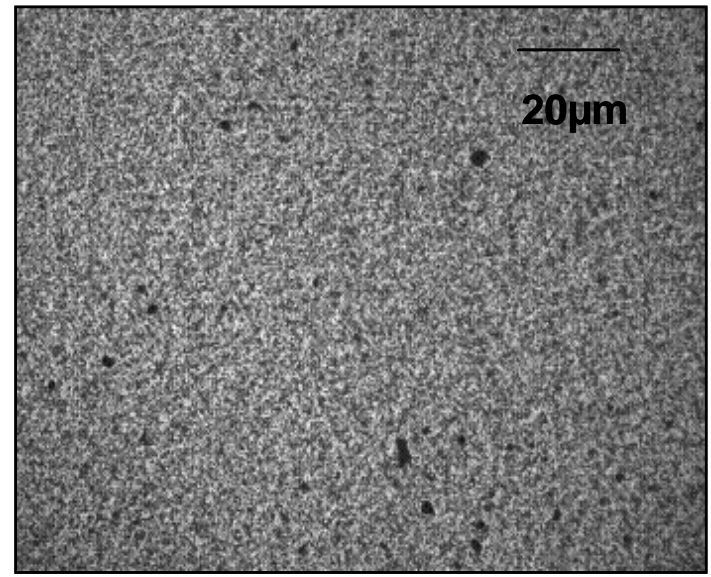

$1.5 \%$ Siloxane

Figure 7a. Optical Micrographs of Siloxane Coated $\mathrm{TiO}_{2}$ dispersed in Paraffin 


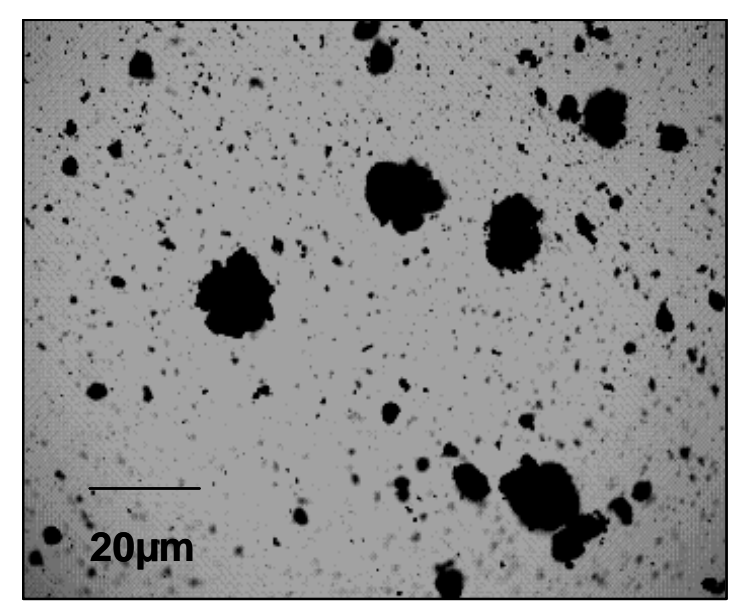

$0.2 \%$ Silane

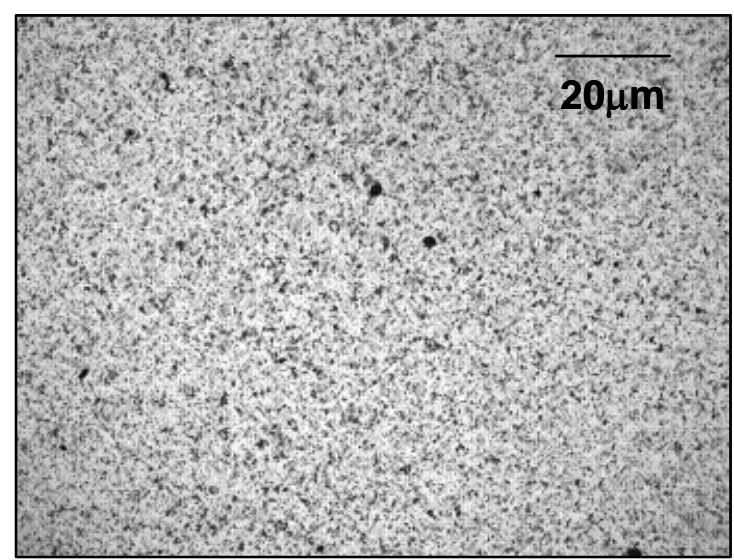

$0.8 \%$ Silane

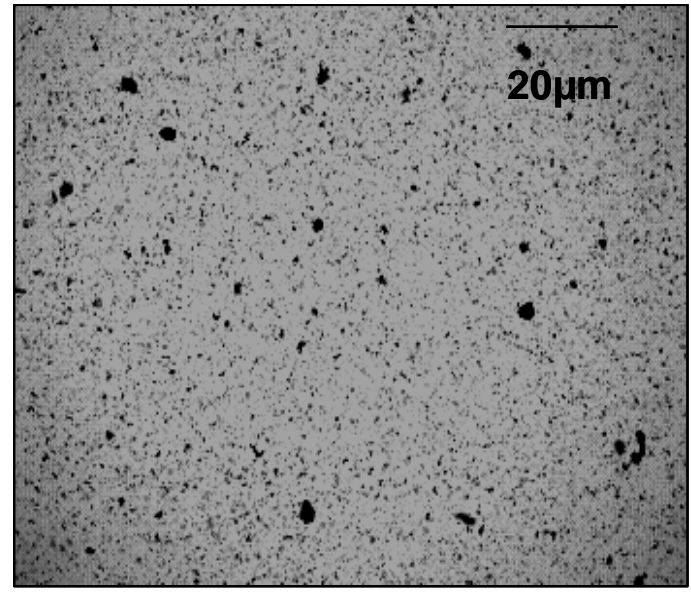

$0.5 \%$ Silane

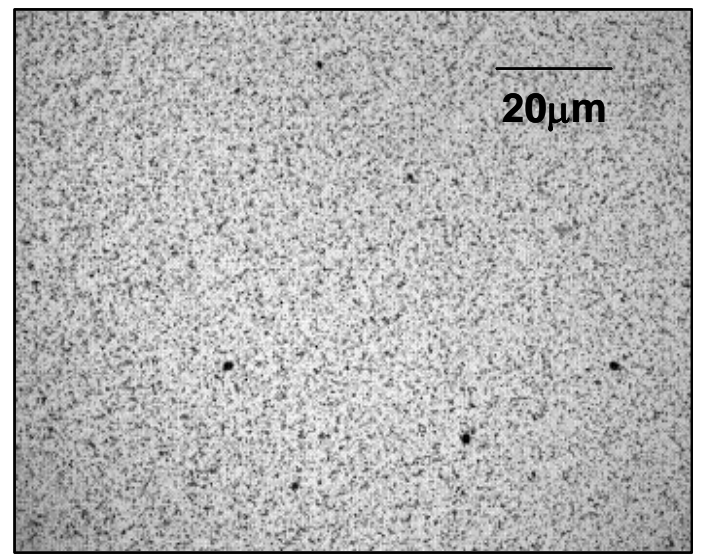

$1.2 \%$ Silane

Figure 7b. Optical Micrographs of Silane Coated $\mathrm{TiO}_{2}$ dispersed in Paraffin

\section{Conclusions}

Contact angle measurements have been carried out on discs pressed from titanium dioxide pigment coated with different levels and two different types of organic compound: polymethylsiloxane and octyl triethoxy-silane. To allow for the fact that measurements were made on pressed particles rather than on a perfectly flat surface, a relationship was derived between the measured contact angle $(\phi)$ and the true Young's contact angle $(\theta)$, as shown in the following equation: $\cos \phi=\frac{\pi}{2 \sqrt{3}} \cdot(1+\cos \theta)^{2}-1$.

This relationship is independent of particle size and was used to correct measured contact angles to derive the true Young's contact angle. 
Surface energy values were derived from the corrected contact angle measurements. It was found that the polar surface energy decreased in value with increasing level of organic coating. The point at which the polar surface energy reduced almost to zero indicated the point at which complete coating coverage was achieved. For both the siloxane and the silane coatings it was found that complete coating coverage occurred at an addition level of around 0.8 weight $\%$. These results were in good agreement with dispersion tests on samples of pigment in liquid paraffin.

\section{Acknowledgements}

The authors would like to acknowledge funding for this work from Huntsman Pigments and the EPSRC. Technical support from Dr. Brian Noble from Huntsman Pigments is much appreciated.

\section{References}

1. S. Valente and R. Butler, Mod. Plast. Int., 24(10) (1994) 77.

2. H.H Murray, Chapter 2 in 'Chemistry of Pigments and Fillers', John Wiley \& sons, Canada (1983).

3. J.G. Balfour, JOCCA, 73(12) (1990) 478.

4. J.H. Braun, A. Baidins and R.E. Marganski, Prog. Org. Coat., 20 (1992) 105.

5. H.G Voelz, G.Koempf, H.G Fitzky, Farbe und Lack, 78, (1972) 1037.

6. R. E. Day, Poly. Deg. \& Stab., 29 (1990) 73.

7. T. Young, Phil. Trans., 95 (1805) 65.

8. A. Dupré, Adv. Colloid Int. Sci., 5 (1950) 514.

9. F.M. Fowkes, Ind.\& Eng. Chem., 56 (1964) 12.

10. D.K. Owens and R.C. Wendt, J. Appl. Poly. Sci., 13 (1969) 1741.

11. D.H. Kaelble and K.C. Uy, J. Adhes., 2 (1970) 50. 
12. I. Sutherland and R.J. Heath, Prog. Rubber \& Plast. Technol., 14(3) (1998) 151.

13. I. Sutherland, D.M. Brewis, R.J. Heath and E. Sheng, J. Surface \& Interfacial Anal., 17 (1991) 505.

14. R.H. Bradley, X. Ling and I. Sutherland, Carbon, 31 (1993) 1115.

15. L. Le Pluart, J. Duchet, H. Sautereau and J.F.Gerard, J Adhes., 78 (2002) 645. 